\title{
Gynecological Complaints and Seeking Medical Help Among Female Adolescents Living in Jeddah, Saudi Arabia
}

\author{
Helen Suban Mohammed Gouse ${ }^{1 *}$, Sherehan Mohammed Ali Wahid², \\ Rana Mohammed Ahmed Garout ${ }^{2}$, Fatema Mohammed Ayub², \\ Mahmoud Abdallah Youssef ${ }^{3}$ and Suban Mohammed Gouse ${ }^{4}$ \\ 'Assistant Professor, Department of Anatomy, Community Coordinator of Medicine Program, Ibn Sina National \\ College for Medical Studies, Jeddah, Saudi Arabia; dr_helenghouse@yahoo.co.in \\ ${ }^{2} \mathrm{lbn}$ Sina National College for Medical Studies, Jeddah, Saudi Arabia \\ 32Department of Obstetrics \& Gynecology, Faculty of Medicine, Ain Shams University, Cairo, Egypt \\ ${ }^{4}$ Department of Microbiology and Pathology, Faculty of Medicine, Ibn Sina National \\ College for Medical Studies, Jeddah, Saudi Arabia
}

\begin{abstract}
The objective of this research is to determine the prevalence of gynecological and menstrual complaints concerning adolescent girls in Jeddah, Saudi Arabia, and exploring their behaviour in reporting them to a medical professional. A cross-sectional survey was conducted at female high schools in the South district of Jeddah, Saudi Arabia from June 2017 to Dec 2019. A sample population of 1931/2406 girls aged between 10-19 years was non-randomly selected to complete a self-reporting questionnaire. The questionnaire included a wide range of symptoms regarding the menstrual cycle and whether the sample sought medical attention. The gynecological complaints from most to least reported include dysmenorrhea (83\%), Premenstrual Syndrome (PMS) (47\%), abnormal vaginal discharge (39\%), irregular menstrual periods (34\%), heavy menstrual bleeding (HMB) (27\%) and amenorrhea (17\%). Overall, over $50 \%$ of the population failed to seek medical attention regarding every complaint, those suffering from breast pain (98\%), abnormal vaginal discharge (92\%), dysmenorrhea (87\%), HMB (79\%) and amenorrhea (78\%). Our findings conclude that regardless of numerous adolescents complaining of gynecological symptoms, less than $50 \%$ of those with a complaint tend to seek medical consultation which may be attributed to lack of health awareness, family support and ongoing social stigma regarding women's reproductive health. Therefore, attention should be given to this adolescent group, guide them and encourage them to seek medical help and improve the primary health care system.
\end{abstract}

Keywords: Abnormal Vaginal Discharge, Adolescents, Dysmenorrhea, Gynecological Complaints, Heavy Menstrual Bleeding, Irregular Menstrual Period, Medical Consultation, Menarche, Primary Health Care, PMS

\section{Introduction}

The World Health Organization defines adolescents as those between 10 to 19 years of age. $20 \%$ of the world's population is comprised of this age group ${ }^{1}$. Saudi Arabia is home to more than 34 million people, around half of which are females, of which almost 2.5 million are female adolescents $^{2}$. The younger generation has been a recent

*Author for correspondence 
focus in global health during the past decade compared to the previous focus on maternal and child health ${ }^{3}$. The barriers of inexperience and inability to access information regarding healthcare have changed in Saudi Arabia during the past few years with digital media exposure. Currently the system is shifting towards a primary healthcare system as per the vision of $2030^{4}$, which will hopefully increase and advocate female adolescent's health.

Adolescence is the phase of physical, social and psychological change and maturation from childhood to adulthood $^{5}$. The menstrual cycle is part of the changes in the reproductive system that takes place in a female's body. Menstruation is the shedding of the functional is layer of the endometrium ${ }^{6,7}$. It results when fertilization and implantation do not take place, and marks the beginning of a new menstrual cycle ${ }^{7}$. The average age of menarche or initial age of first menses is $12-13$ years of age $^{8}$. Early menarche is considered to be less than 9 years and late menarche is either at or after 15 years of age 9 There are females who may reach 16 years of age without experiencing the first menses and this is called primary amenorrhea. Secondary amenorrhea is termed as menses that has been absent for 6 months or absent for 3 normal cycles $^{10,11}$. The menstruation cycle recurs every 21 to 35 days, with a median of 28 days $^{8,11}$. If the cycle takes place more than 35 days, this can be termed as oligomenorrhea ${ }^{9}$. The period of menstruation lasts for 3 to 7 days and on average 5 days ${ }^{7,11}$. In addition, the normal amount of blood loss is around $30 \mathrm{~mL}$, however, a loss of more than $80 \mathrm{~mL}$ is then termed as heavy menstrual bleeding $(\mathrm{HMB})^{11}$.

Cyclic painful menstruation or dysmenorrhea is the most common symptom during the menstrual phase of the endometrium ${ }^{12}$. Primary dysmenorrhea describes excessive release of prostaglandins due to endometrial cell lysis, and increased uterine contractions ${ }^{12}$. This pain usually starts hours before or after the onset of menstruation and can last for 2-3 days. Premenstrual syndrome (PMS) describes the disorders that occur due to changes in the hormonal system during the luteal phase of the ovarian cycle. These conditions include physical symptoms like bloating, weight gain, breast swelling and tenderness, and acne. In addition, there are psychological symptoms such as mood changes, depressed mood, anxiety, and emotional liability that can affect a female's daily life ${ }^{13}$.
The first sign of a female's reproductive maturation and fertility is menstruation ${ }^{14}$. A regular menstruation with normal functioning of the ovaries and endometrium is an indicator of fertility and reproductive ability. The absence of normal functioning menstruation may suggest that pathology may be present and further testing may be required. Like many other countries in Asia and Africa, the cultural norms of Saudi society may contribute to why its females are hesitant to discuss gynecological health. This leads both young and older women to disregard their health concerns in fear of embarrassment ${ }^{15}$. Adolescents undergo developmental changes in their body but are not well informed on normal physiology. Adolescents tend to disregard their symptoms and delay seeking medical attention owing to lack of education, family support, public awareness or social rules.

The aim of this study is to promote female adolescent health. The objectives of this study include exploring the prevalence of common gynecological problems affecting adolescent females in Jeddah, Saudi Arabia and identifying their level of confidence in reporting these problems.

\section{Methodology}

A cross sectional survey was conducted at female high schools in Jeddah, Saudi Arabia, within the South district using non-randomized convenient sampling with consecutive techniques. A total of 2,406 adolescent girls aged $10-19$ were included in this study. The sample size was calculated using Raosoft software with an estimate of $50 \%$ response distribution, within a margin error of $5 \%$, and $95 \%$ confidence interval. The recommended minimum was 385 students. The inclusion criteria included participants within the adolescent range of 10 to 19 years, as well as adolescents of both Saudi and nonSaudi populations. Exclusion criteria were participants who did not accept their data to be used in this research, those who did not complete all the survey items, and those who were out of the age range of adolescents. The investigation was confirmed with the principles described in the Declaration of Helsinki of 1964.

The study used a modified questionnaire with 36 items ${ }^{16}$. Data of sections consisted of socio-demographic details, gynecological complaints and behaviour towards seeking medical consultation. The data was collected 
from June 2017 - Dec 2019. Trained medical students distributed a self- administered questionnaire to schools. School visits were prepared to be under the campaign "Common Gynecological complaints among teenagers", as part of the community services at Ibn Sina National College for Medical Studies (ISNC).

Data was analyzed using Microsoft Office Excel and Statistical Package for the Social Sciences (IBM SPSS Statistics 26). Qualitative data was conveyed as frequency and percentage for different variables.

\subsection{Ethical Consideration}

The study was approved by the Research Ethical Committee Board of ISNC, Jeddah (H-04-15062016). Participation was voluntary with students, parents and school administration consent and details were kept confidential.

\section{Results}

A total of 2406 survey responses were obtained. According to the inclusion and exclusion criteria, 475 were excluded and the study consisted of 1931 subjects. Most of the sample consisted of Saudi females (69\%) of various age groups, mostly 16 to 17 years of age (42\%) and high school students (65\%). Majority of the sample (35\%) consisted of females between 41 to 50 kilograms. More than half of the sample (57\%) had their first menses at 12 to 13 years of age (see table 1).

Most female adolescents complained of dysmenorrhea (83\%). Out of whom $81 \%$ complained of pain for the first few hours to two days of their period. There were $12 \%$ who complained of pain that starts before, increases during, and stops after their menstruation. While, $7 \%$ complained of pain throughout their menstrual period. An average of $75 \%$ complained of symptoms of PMS, mainly emotional changes (75\%) that included nervousness, irritability and sensitivity before their menstrual period. Additionally, there were adolescents who complained of irregular menstruation (34\%), heavy menstrual bleed (27\%), amenorrhea (17\%), abnormal vaginal discharges (39\%), and hirsutism (11\%) (see table 2).

Out of 1594 participants who suffered from dysmenorrhea, only 212 (13\%) decided to seek medical advice and 1382 chose not to, the majority of whom (44\%) resorted to using oral painkillers. Out of the
Table 1. Frequency and percentage of sociodemographic characteristics $(\mathrm{n}=1931)$

\begin{tabular}{|c|c|c|c|}
\hline \multicolumn{2}{|l|}{ Details } & Frequency & Percentage \\
\hline \multirow[t]{2}{*}{ Nationality } & Non - Saudi & 601 & $31.1 \%$ \\
\hline & Saudi & 1330 & $68.9 \%$ \\
\hline \multirow{5}{*}{$\begin{array}{l}\text { Current } \\
\text { Age }\end{array}$} & 10 to 11 & 8 & $0.4 \%$ \\
\hline & 12 to 13 & 61 & $3.2 \%$ \\
\hline & 14 to 15 & 339 & $17.6 \%$ \\
\hline & 16 to 17 & 809 & $41.9 \%$ \\
\hline & 18 to 19 & 714 & $37.0 \%$ \\
\hline \multirow[t]{5}{*}{$\begin{array}{l}\text { Level of } \\
\text { Education }\end{array}$} & $\begin{array}{l}\text { Elementary } \\
\text { School }\end{array}$ & 19 & $1.0 \%$ \\
\hline & Middle School & 320 & $16.6 \%$ \\
\hline & High School & 1254 & $64.9 \%$ \\
\hline & College & 324 & $16.8 \%$ \\
\hline & $\begin{array}{l}\text { Not currently } \\
\text { studying }\end{array}$ & 14 & $0.7 \%$ \\
\hline \multirow[t]{6}{*}{ Weight } & $35-40 \mathrm{~kg}$ & 270 & $14.0 \%$ \\
\hline & $41-50 \mathrm{~kg}$ & 675 & $35.0 \%$ \\
\hline & $51-60 \mathrm{~kg}$ & 584 & $30.2 \%$ \\
\hline & $61-70 \mathrm{~kg}$ & 272 & $14.1 \%$ \\
\hline & $71-80 \mathrm{~kg}$ & 97 & $5.0 \%$ \\
\hline & more than $80 \mathrm{~kg}$ & 33 & $1.7 \%$ \\
\hline \multirow{4}{*}{$\begin{array}{l}\text { Age of } \\
\text { Menarche }\end{array}$} & 10 to 11 & 321 & $16.6 \%$ \\
\hline & 12 to 13 & 1100 & $57.0 \%$ \\
\hline & 14 to 15 & 474 & $24.5 \%$ \\
\hline & 16 to 17 & 36 & $1.9 \%$ \\
\hline
\end{tabular}

participants who had dysmenorrhea for a concerning period of time (19\%) only $23 \%$ sought medical advice. Similarly, from the 869 subjects who experienced breast pain in the days before their menstruation, the majority did nothing (76\%) and only $126(2 \%)$ consulted a doctor, whereas $12 \%$ took over-thecounter painkillers and $10 \%$ wore a bra to relieve the pain. In addition to that, from the 514 who reported having heavy menstrual bleeds and from the 324 who reported having amenorrhea, a small percentage of $21 \%$ and $22 \%$, respectively, went to see the doctor for a consultation. Regarding the 746 participants who reported experiencing abnormal vaginal discharge, a high percentage of $92 \%$ of the females chose to not seek medical advice. For every complaint mentioned, more 
Table 2. Frequency and percentage of female adolescents with complaints

\begin{tabular}{|c|c|c|c|}
\hline \multicolumn{2}{|l|}{ Gynecological complaints } & Frequency & Percentage \\
\hline \multicolumn{2}{|l|}{ Dysmenorrhea } & 1627 & $82.5 \%$ \\
\hline \multirow[b]{5}{*}{ Premenstrual Syndrome (PMS) } & Emotional changes before menstrual period & 1443 & $74.7 \%$ \\
\hline & Acne flare ups before menstrual period & 1038 & $53.8 \%$ \\
\hline & Abdominal distension or bloating before menstrual period & 996 & $51.6 \%$ \\
\hline & Breast pain or tenderness before menstrual period & 869 & $45.0 \%$ \\
\hline & Leg or foot swelling before menstrual period & 225 & $11.7 \%$ \\
\hline \multicolumn{2}{|l|}{ Irregular menstrual period } & 650 & $33.7 \%$ \\
\hline \multicolumn{2}{|l|}{ Heavy menstrual bleeding } & 514 & $26.6 \%$ \\
\hline \multicolumn{2}{|l|}{ Amenorrhea } & 324 & $16.8 \%$ \\
\hline \multicolumn{2}{|l|}{ Abnormal vaginal discharges } & 746 & $38.6 \%$ \\
\hline \multicolumn{2}{|l|}{ Hirsutism } & 218 & $11.3 \%$ \\
\hline
\end{tabular}

than $50 \%$ of the adolescence chose to not get medical advice (see figure 1).

There were 70 out of the 107 adolescent females who consulted their doctors for HMB and were asked to undergo an ultrasound, in which more than half showed a normal uterus and ovaries (56\%) and the rest (44\%) with ovarian cysts.

This study included 71 participants who consulted their doctors for amenorrhea and 51 (72\%) of them had an investigation like ultrasound. Normal results were found in 23 (45\%) of the subjects, whereas 20 (39\%) had cystic ovaries and $8(16 \%)$ had other ultrasound findings, as shown in (figure 2).

Moreover, figure 3 shows how the family members and friends of the participants reacted to their emotional changes experienced as a part of PMS. More than half of the subjects $(51 \%)$ did not receive any help or support during PMS and almost one third (28\%) felt that family increased the patient's nervousness.

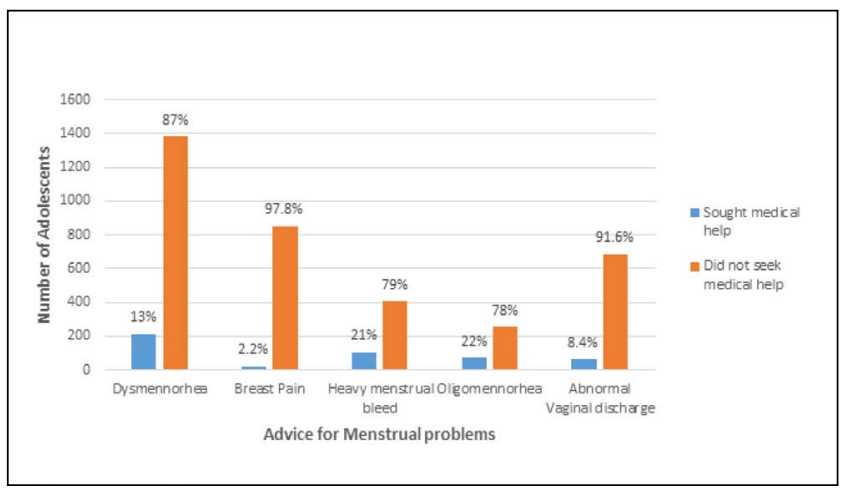

Figure 1. Adolescents seeking medical help for their menstrual problems.

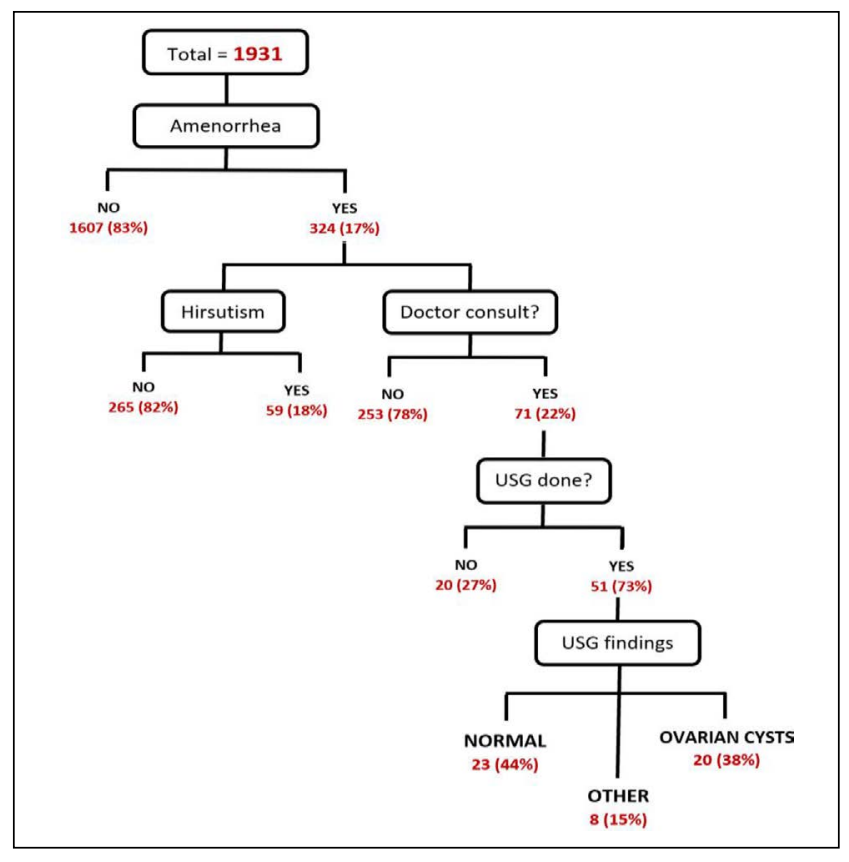

Figure 2. Reporting status of Amenorrhea.

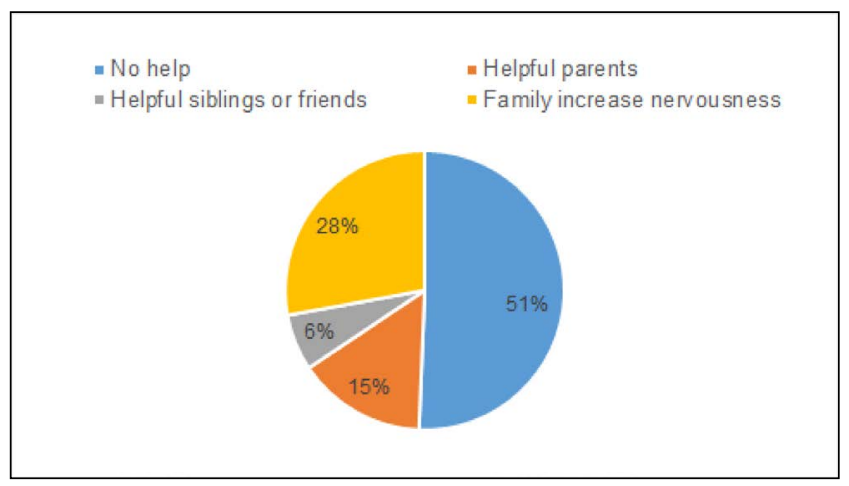

Figure 3. Family/Friends support for girls with PMS. 


\section{Discussion}

The most common gynecological symptoms reported in the present study were primary dysmenorrhea (84\%), followed by PMS (75\%) and irregular menstruation (34\%). A high percentage of $87 \%$ participants did not seek medical consultation regarding dysmenorrhea. This may be due to the presence of tolerable pain, and general reassurance from the female members of the community. However true reassurance from the primary healthcare is appreciated to differentiate between normal and abnormal pain.

Although primary dysmenorrhea can be treated with self-medication like non-steroidal-anti-inflammatory drugs (NSAIDs), a high usage of NSAIDs, adequate therapeutic dosage, frequency and change in treatment should be enforced by the primary physician ${ }^{17}$. Regarding the duration of pain, $19 \%$ reported severity of cyclic pain, of which only $23 \%$ consulted the doctor. Abnormal characteristics such as continuous or worsened pain can suggest secondary dysmenorrhea, which needs to be evaluated further.

The second common symptom found is PMS (75\%), which agreed with a UAE study ${ }^{16}$. About $60 \%$ of physicians had not asked patients about symptoms of PMS during routine appointments ${ }^{16}$. Providing the scientific information that PMS is normal in many female adolescents may reassure parents and increase their empathy by encouraging them to offer emotional support to their daughter. All symptoms of PMS were reported to have disappeared with the beginning of the menstrual period in two thirds of the population, which is physiologically expected.

Majority of the study population had their first menstruation between 12-13 years, similar to numerous studies conducted previously ${ }^{18,19,20}$. It was suggested that early menarche is associated with risk of type 2 diabetes and cardiovascular disease ${ }^{21,22}$. Late menarche of 16-17 years (nearly 2\%) in our study can have increased risk of major adverse cardiovascular event ${ }^{23}$, however another study has suggested that late menarche is associated with reduced risk of endometrial cancer ${ }^{24}$.

Heavy menstrual bleeding is present in $27 \%$ of the study sample, which is similar to a previously carried out WHO study ${ }^{25}$. In addition, 107 out of the current study's 514 participants with HMB had consulted a doctor.
The low number of reported cases $(21 \%)$ suggests that adolescents often overlook this gynecological concern, which can lead to severe anemia if left untreated. However, of the 107 that obtained medical consultation, 70 had an ultrasonography (USG) done of which more than half (56\%) showed normal results. The 407 patients who did not consult a doctor should be made aware that seeking medical attention might help in early diagnosis of gynecological illnesses or reassurance of a healthy body. On the other hand, USG of 31 out of 70 subjects showed ovarian cysts. According to the International Federation of Gynecology and Obstetrics (FIGO) possible etiologies of abnormal uterine bleeding ${ }^{26,27}$ does not include ovarian cysts, therefore, unfortunately, this finding in our subjects cannot be explained.

In the study, 34\% reported oligomenorrhea and 17\% experienced amenorrhea of which $49 \%$ sought medical attention, indicating that it was the most concerning symptom as compared to dysmenorrhea $(12 \%)$ and HMB (21\%). Such menstrual abnormalities can be seen in patients with polycystic ovarian syndrome (PCOS). Additionally, from those suffering with amenorrhea $(n=324), 59$ reported to have hyperandrogenism in the form of hirsutism. A study performed in 2008 has shown that the common cause of hirsutism was PCOS ${ }^{28}$. Majority of the population with amenorrhea had a pelvic USG done to visualize their uterus and ovaries. Rotterdam criteria suggest a PCOS diagnosis when 2 out of 3 criteria for PCOS are met: ovulatory dysfunction (amenorrhea, oligomenorrhea), hyperandrogenism, and ovarian cysts seen on $\mathrm{USG}^{29}$. Ovarian cysts were discovered in 20 out of $324(6 \%)$, a small significant group of patients who should maintain their medical consultations to prevent subfertility. PCOS may have increased risk of developing endometrial cancer, breast cancer, type 2 diabetes, cardiovascular diseases, and infertility ${ }^{30}$.

Only about half ( $\mathrm{n}=1050)$ of the sample was aware of physiological vaginal discharge. Half of the participants who experienced abnormal vaginal discharge had burning or itching sensations. Only an alarming 8\% sought treatment from a doctor. Patients may refrain from addressing this symptom out of fear of embarrassment as they may associate vaginal discharge with poor hygiene practices. However, the most common cause of abnormal vaginal discharge is vulvovaginitis caused by bacterial, yeast or trichomonas infection ${ }^{31}$. This corresponds with 
a Swiss study showing that the highest (92\%) reported symptom in preadolescent girls with vulvovaginitis was vaginal discharge ${ }^{32}$. Therefore, treatment must be emphasized, as ignorance may lead to severe discomfort and widespread infection.

Puberty has been influenced by socio-demographic factors, genetic factors, race, socio-economic status, and diet $^{33}$. Although certain factors cannot be changed, it is still under primary healthcare jurisdiction to encourage both patients and parents to follow a healthier lifestyle in general, which could have a positive impact on the reproductive system. This is in accordance to Saudi Arabia's vision 2030, which plans to steer first contact of patients to a family physician ${ }^{4}$.

\section{Conclusion}

The gynecological complaints from most to least reported include dysmenorrhea, premenstrual syndrome (PMS), abnormal vaginal discharge, irregular menstrual period, HMB and amenorrhea. Overall more than half the population failed to seek medical attention regarding each complaint. This may be attributed to their lack of health awareness, family support, or social stigma.

We recommend conducting more awareness programs for adolescent females and their parents, to empower and educate them about their reproductive health. Current and future family physicians should be aware of the need to properly educate and listen to the adolescent population. Hence reducing the social stigma associated with issues related to reproductive health. We also encourage seeking medical help at primary health care centers for reassurance, early prevention and management of gynecological conditions.

\section{Limitations}

The non- randomized cross sectional study with recall bias limits the estimation of actual prevalence of gynecological symptoms and generalizes the whole age group. Reports of heavy menstrual bleeding were purely subjective and the subjects may have not been aware of the physiological quantity of menstrual bleeding.

\section{Acknowledgements}

We would like to thank Prof. Intessar Emam Sultan, Professor, Head of Department of Medicine, Ibn Sina National College for Medical Studies in helping us to do the statistics related to the study. We thank all the participants who agreed to complete the survey, their parents and school administration.

\section{Disclosure}

Authors have no conflict of interests, and the work was not supported or funded by any drug company.

\section{References}

1. Adolescent health [Internet]. World Health Organisation. [cited 10 Mar 2021]. Available from: https://www.who.int/ westernpacific/health-topics/adolescent-health

2. Alghamdi A. Population in Saudi Arabia by Gender, Age, Nationality (Saudi/Non-Saudi) - Mid 2016 A.D [Internet]. General Authority for Statistics. 2017 [cited 10 Mar 2021]. Available from: https://www.stats.gov.sa/en/5305

3. Azzopardi PS, Hearps SJC, Francis KL, Kennedy EC, Mokdad AH, Kassebaum NJ, et al. Progress in adolescent health and wellbeing: tracking 12 headline indicators for 195 countries and territories, 1990-2016. Lancet Lond Engl. 16 Mar 2019; 393(10176): 1101-18. https://doi. org/10.1016/S0140-6736(18)32427-9

4. Caring for our health | Saudi Vision 2030 [Internet]. [cited 10 Mar 2021]. Available from: https://www.vision2030.gov. sa/en/node/68

5. Adolescent Development [Internet]. Cleveland Clinic. [cited 10 Mar 2021]. Available from: https://my.clevelandclinic.org/health/articles/7060-adolescent-development

6. Garry R, Hart R, Karthigasu KA, Burke C. Structural changes in endometrial basal glands during menstruation. BJOG Int J Obstet Gynaecol. 2010; 117(10): 1175-85. https://doi.org/10.1111/j.1471-0528.2010.02630.x

7. Hacker NF, Gambone JC, Hobel CJ. In: Hacker and Moore's Essentials of Obstetrics \& Gynecology. $6^{\text {th }}$ ed. Philadelphia: Elsevier; 2016. p. 37.

8. Hacker NF, Gambone JC, Hobel CJ. In: Hacker and Moore's Essentials of Obstetrics \& Gynecology. $6^{\text {th }}$ ed. Philadelphia: Elsevier; 2016. p. 15.

9. Lacroix AE, Gondal H, Langaker MD. Physiology, Menarche. In: StatPearls [Internet]. Treasure Island (FL): StatPearls Publishing; 2021 [cited 10 Mar 2021]. 
10. Hacker NF, Gambone JC, Hobel CJ. In: Hacker and Moore's Essentials of Obstetrics \& Gynecology. 6th ed. Philadelphia: Elsevier; 2016. p. 380.

11. Bradley LD. Chapter 10 - Investigation of Abnormal Uterine Bleeding in Premenopausal Women. In: Bradley LD, Falcone T, editors. Hysteroscopy [Internet]. Philadelphia: Mosby; 2009 [cited 10 Mar 2021]. p. 95-114. Available from: https://www.sciencedirect.com/science/article/pii/ B9780323041010500163. https://doi.org/10.1016/B978032304101-0.50016-3

12. Hacker NF, Gambone JC, Hobel CJ. In: Hacker and Moore's Essentials of Obstetrics \& Gynecology. $6^{\text {th }} \mathrm{ed}$. Philadelphia: Elsevier; 2016. p. 266-75.

13. Hacker NF, Gambone JC, Hobel CJ. In: Hacker and Moore's Essentials of Obstetrics \& Gynecology. $6^{\text {th }}$ ed. Philadelphia: Elsevier; 2016. p. 414-8.

14. Komura H, Miyake A, Chen CF, Tanizawa O, Yoshikawa H. Relationship of age at menarche and subsequent fertility. Eur J Obstet Gynecol Reprod Biol. 13 May 1992; 44(3):2013. https://doi.org/10.1016/0028-2243(92)90099-K

15. Aldosari $H$. The effect of gender norms on women's health in Saudi Arabia [Internet]. The Arab Gulf States Institute in Washington. 2 May 2017 [cited 10 Mar 2021]. Available from: https://agsiw.org/wp-content/uploads/2017/05/ Aldosari_Womens-Health_Online-1.pdf

16. Rizk DEE, Mosallam M, Alyan S, Nagelkerke N. Prevalence and impact of premenstrual syndrome in adolescent schoolgirls in the United Arab Emirates. Acta Obstet Gynecol Scand. 2006; 85(5): 589-98. https://doi. org/10.1080/00016340600556049

17. Dysmenorrhea and Endometriosis in the Adolescent [Internet]. American College of Obstetricians and Gynecologists. [cited 10 Mar 2021]. Available from: https://www.acog.org/en/Clinical/Clinical Guidance/ Committee Opinion/Articles/2018/12/Dysmenorrhea and Endometriosis in the Adolescent

18. Omidvar S, Amiri FN, Bakhtiari A, Begum K. A study on menstruation of Indian adolescent girls in an urban area of South India. J Fam Med Prim Care. 2018; 7(4): 698-702. https://doi.org/10.4103/jfmpc.jfmpc_258_17

19. Shaik SA, Hashim RT, Alsukait SF, Abdulkader GM, AlSudairy HF, AlShaman LM, et al. Assessment of age at menarche and its relation with body mass index in school girls of Riyadh, Saudi Arabia. Asian J Med Sci. 5 Nov 2015; 7(2): 5-12. https://doi.org/10.3126/ajms.v7i2.13439

20. Al-Awadhi N, Al-Kandari N, Al-Hasan T, AlMurjan D, Ali S, Al-Taiar A. Age at menarche and its relationship to body mass index among adolescent girls in Kuwait. BMC Public
Health. 12 Jan 2013; 13: 29. https://doi.org/10.1186/14712458-13-29

21. Dreyfus JG, Lutsey PL, Huxley R, Pankow JS, Selvin E, Fernández-Rhodes $\mathrm{L}$, et al. Age at menarche and risk of type 2 diabetes among African-American and white women in the Atherosclerosis Risk in Communities (ARIC) study. Diabetologia. Sep 2012; 55(9): 2371-80. https://doi. org/10.1007/s00125-012-2616-Z

22. Feng Y, Hong X, Wilker E, Li Z, Zhang W, Jin D, et al. Effects of age at menarche, reproductive years, and menopause on metabolic risk factors for cardiovascular diseases. Atherosclerosis. Feb 2008; 196(2): 590-7. https://doi. org/10.1016/j.atherosclerosis.2007.06.016

23. Lee JJ., Cook-Wiens G, Johnson BD, Braunstein GD, Berga SL, Stanczyk FZ, et al. Age at Menarche and Risk of Cardiovascular Disease Outcomes: Findings From the National Heart Lung and Blood Institute-Sponsored Women's Ischemia Syndrome Evaluation. J Am Heart Assoc. 18 Jun 2019; 8(12): e012406. https://doi.org/10.1161/ JAHA.119.012406

24. Dossus L, Allen N, Kaaks R, Bakken K, Lund E, Tjonneland A. et al. Reproductive risk factors and endometrial cancer: the European Prospective Investigation into Cancer and Nutrition. Int J Cancer. 15 Jul 2010; 127(2): 442-51.

25. Harlow SD, Campbell OM. Menstrual dysfunction: a missed opportunity for improving reproductive health in developing countries. Reprod Health Matters. May 2000; 8(15):142-7. https://doi.org/10.1016/S09688080(00)90016-8

26. Munro MG, Critchley HO, Fraser IS, FIGO Menstrual Disorders Working Group. The FIGO classification of causes of abnormal uterine bleeding in the reproductive years. Fertility and sterility. Jun 1, 2011; 95(7): 2204-8.

27. Noel S. Histopathological pattern of benign ovarian tumours in a tertiary care hospital in rural Telangana: 5-year retrospective study. International Journal of Medical Science and Diagnosis Reserach. 27 Feb 2019 [cited 10 Mar 2021]; 3(2): 154-158.

28. Al-Ruhaily Atallah D., Malabu Usman H., Sulimani Riad A. Hirsutism in Saudi females of reproductive age: a hospital-based study. Ann Saudi Med. 1 Jan 2008; 28(1): 28-32. https://doi.org/10.5144/0256-4947.2008.28

29. Williams T, Mortada R, Porter S. Diagnosis and Treatment of Polycystic Ovary Syndrome. Am Fam Physician. 15 Jul 2016; 94(2): 106-13.

30. Daniilidis A, Dinas K. Long term health consequences of polycystic ovarian syndrome: a review analysis - PubMed. Hippokratia. 2009; 13(2): 90-2. 
31. Vaginitis - Symptoms and causes [Internet]. Mayo Clinic. [cited 2021 Mar 10]. Available from: https://www.mayoclinic.org/diseases-conditions/vaginitis/symptoms-causes/ syc-20354707

32. Stricker T, Navratil F, Sennhauser FH. Vulvovaginitis in prepubertal girls. Arch Dis Child. 1 Apr 2003; 88(4): 324-6. https://doi.org/10.1136/adc.88.4.324
33. Eid AA, Alabbad S, Tatwany B, Aljahdali A. Menarche Age of Mothers and Daughters and Correlation between them in Saudi Arabia. Reproductive System \& Sexual Disorders. 11 Sept 2015 [cited 10 Mar 2021]; 04(03). https://doi. org/10.4172/2161-038X.1000153 